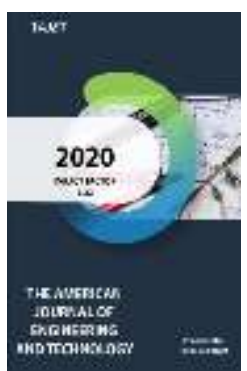

Journal Website: http://usajournalshub.c om/index,php/tajet

Copyright: Original content from this work may be used under the terms of the creative commons attributes 4.0 licence.

\section{Improvement Of Geodetic Support During The Construction Of Long-Distance Linear Structures Using GPS Technologies}

\author{
Askar Anvarovich Kadirov \\ Master Of 2 Course, Tashkent Institute Of Architecture And Civil Engineering, Tashkent, \\ Uzbekistan
}

\title{
ABSTRACT
}

This research paper provides an improvement in geodetic support during the construction of longdistance linear structures using modern GPS technologies. When performing hydrographic surveys using the global navigation satellite systems GPS, the tack is laid along the project lines determined during the planning of the hydrographic survey.

\section{KEYWORDS}

Improvement, geodetic support, construction, of long-distance linear structures, GPS, technologies.

\section{INTRODUCTION}

Depth measurements are made along lines crossing the reservoir and located at a known distance from each other. Plans are drawn up in isobaths in those cases when they are intended for the design of activities directly related to the exploitation of water areas, and the depths must be shown on them. For the design of construction objects on the water, adjacent to the shore, the bottom relief on the plans is depicted in horizontals.

Depth measurements are classified according to several criteria:

1. on the details of the measurement;

2. by the ways of laying the tacks; 
3. by the methods of determining the place on the tacks;

4. by methods of measuring depths.

In terms of details, depth measurements are divided into special, detailed and lightweight.

\section{METHODS OF RESEARCH}

Each of these types of soundings has its own frequency of tacks and measured depths on them, as well as the scale of the plan. The main scales for drawing up survey plans in accordance with the accepted classification of measurements in detail and the corresponding tack frequency, taking into account the complexity of the bottom relief, are given in Table. 1.

The height of the bottom relief section when depicted by isobaths or horizontals is:

1. For special and detailed measurements - $0.5 \mathrm{~m}$ at depths up to $10 \mathrm{~m}$;

2. For lightweight and reconnaissance measurements - $0.5 \mathrm{~m}$ - for depths less than $5 \mathrm{~m}$ and $1.0 \mathrm{~m}$ - for depths over $5 \mathrm{~m}$.
According to the methods of laying tacks, measurements are distinguished:

1. Along the project lines;

2. Along the coastal sections;

3. By coastal landmarks;

4. By gyrocompass or magnetic compass;

5. By isophasometer and path indicator;

6. In a pendulum way.

According to the methods of determining the place on the tack, measurements are divided into the following:

> Using satellite geodetic receivers;

$>$ No instrumental serifs;

With instrumental serifs;

> With instrumental serifs from the shore or boat;

$>$ With direct breakdown of measurement points;

$>$ Using phase systems.

The method for determining the location on the tack is established in each individual case, proceeding from the adopted measurement details, the current speed, the distance of the measurement site from the coast, the scale of the plan, and depending on the availability of certain instruments.

Table 1. The method of determining the location on the tack when drawing up the scale of the plan and depending on the availability of certain instruments

\begin{tabular}{|c|c|c|c|c|c|}
\hline \multirow{2}{*}{$\begin{array}{c}\text { Measurement } \\
\text { detail }\end{array}$} & \multirow[b]{2}{*}{$\begin{array}{l}\text { Scale of the } \\
\text { plan }\end{array}$} & \multicolumn{2}{|c|}{ Distance between tacks, $\mathbf{m}$} & \multicolumn{2}{|c|}{ Distance between measurement points, $m$} \\
\hline & & $\begin{array}{c}\text { in difficult } \\
\text { terrain }\end{array}$ & in calm terrain & in difficult terrain & in calm terrain \\
\hline \multirow[t]{2}{*}{ Special } & $1: 500$ & 5 & 10 & 2 & 5 \\
\hline & $1: 1000$ & 10 & 20 & 5 & 10 \\
\hline \multirow[t]{3}{*}{ Detailed } & $1: 2000$ & 20 & 40 & 10 & 20 \\
\hline & $1: 5000$ & 50 & 100 & 20 & 30 \\
\hline & $1: 10000$ & 100 & 200 & 30 & 40 \\
\hline \multirow[t]{3}{*}{ Lightweight } & $1: 2000$ & 40 & 60 & 10 & 20 \\
\hline & $1: 5000$ & 100 & 150 & 20 & 30 \\
\hline & $1: 10000$ & 200 & 300 & 30 & 40 \\
\hline
\end{tabular}

Regardless of the accepted method for determining the location on the tack, the error of the planned position of the measured points should not exceed the values given in table 2: 
Doi: https://doi.org/10.37547/tajet/Volume02Issue09-02

Table 2. Determination of the location on the tacks, the error of the planned position of the measured points

\begin{tabular}{|c|c|}
\hline Measure & Error, $\mathbf{m m}$, on the scale of the plan \\
\hline Special & 1,5 \\
\hline Detailed & 1,5 \\
\hline Lightweight & 2,0 \\
\hline
\end{tabular}

When performing hydrographic surveys using global navigation satellite systems GPS, the laying of the tacks is carried out along the project lines (planned tacks) determined in the process of planning the hydrographic survey.

Hydrographic survey planning is carried out using special software packages for hydrographic surveys: Haypack (Germany), Navisoft (Denmark) and others. The position of the project lines can be specified by the coordinates of the end points or generated automatically. In the process of planning a hydrographic survey, other data are also prepared:

The boundaries of the area within which the survey is to be performed and the scale of the map (plan) are set;

$>$ The orientation and size of the map sheet (plan) is selected;

$>$ Set the type of the coordinate grid and its orientation relative to the vertical frames of the map (plan);

$>$ The title of the map (plan) is determined;

$>$ The coordinates of points of objects (coastlines, navigation signs, etc.) are set.

All data prepared in the process of planning a hydrographic survey are presented in the form of a map and displayed on the monitor of the ship's post. Measurement results and edited data can later be presented on the same map.
Hydrographic software packages include programs that include, among other things, graphically guiding the helmsmen on board with an offset indicator that shows the distance from the planned tack line.

In cases where the projected sections serve as one of the position lines (when measuring along a marked line or along sections with notches with one instrument), their breakdown on the ground is carried out especially carefully and is carried out from the pickets of the survey line, which is laid parallel to the coastline.

The measuring line is laid with a theodolite course with a relative error of at least 1: 2000.

The line pickets are split at the distances corresponding to the accepted between tacks.

Gates are split from the main pickets by the theodolite at an angle set to the direction of the main line and can provide the position of both parallel and radial tacks.

Radial tacks are laid on sharp bends in the coastline between two adjacent sections with parallel tacks (Fig. 1). 


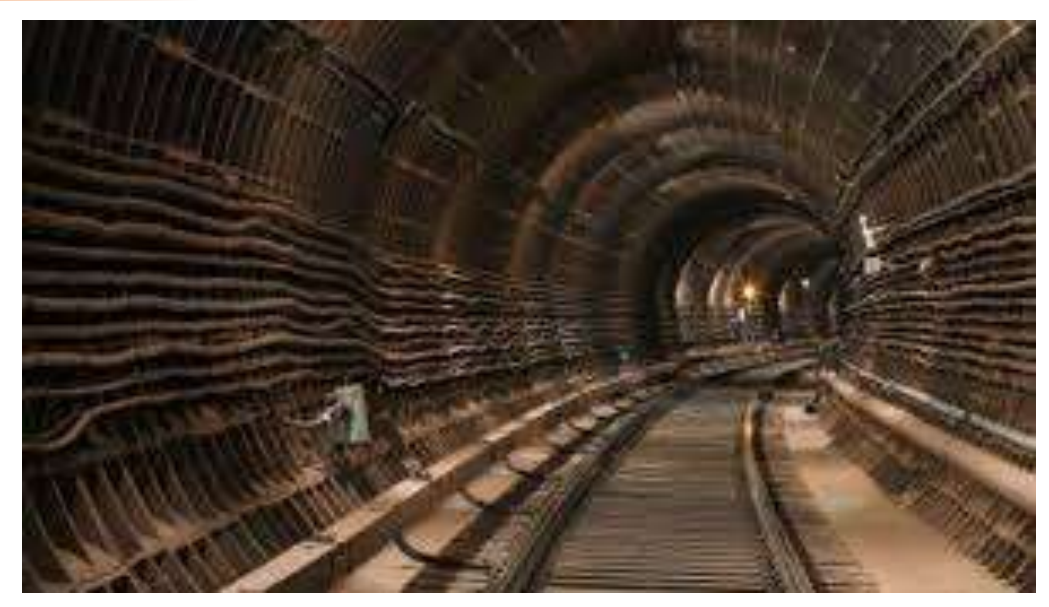

Fig. 1. Stakeout of radial tacks

The angle between the lines of the radial tacks is calculated (from the condition that the maximum distances between the tacks at the end points do not exceed the specified intertack distance) by the formula:

$$
\alpha=57,3^{\circ} \frac{\mathrm{m}}{\mathrm{s}}
$$

where $\mathbf{m}$ - is the distance between the tacks at the outer edge of the measurement site, $\mathrm{m}$;

$\mathbf{S}$ - is the distance from the leading points pole to the end of the tack in $\mathrm{m}$.

The distances between the front and rear leaf points are calculated based on the given sensitivity of the alignment and the length of the tack by the formula:

$$
d=\frac{D^{2}}{1,72 E_{0}-D^{\prime}}
$$

where $\mathbf{d}$ - is the distance between the leading points in $\mathrm{km}$;

$\mathbf{E}_{\mathbf{0}}$ - permissible error in determining the location of depths for a given type of sounding in $\mathrm{m}$;

D- is the tack length in $\mathrm{km}$ from the leading leading point to the end.

It is also allowed to hang the leading line (tack) on the water using a theodolite.

\section{CONCLUSION}

Consequently, in the case when the crossings are intended only for orientation on tacks, their breakdown on the ground can be performed in a simplified way using a goniometer and a steel cable, the length of which corresponds to a given inter-haul distance.

The distance between the lead points, in this case, must be at least $0.04 \mathrm{D}$, where $\mathrm{D}$ is the distance from the lead lead point to the end of the tack.

\section{REFERENCES}

1. Teunissen P. J. G., Kleusberg A. (ed.). GPS for Geodesy. - Springer Science \& Business Media, 2012.

2. Schulz T. Calibration of a terrestrial laser scanner for engineering geodesy. - ETH Zurich, 2008. 96 p.

3. Karev, P.A. On the need to revise the status and technical parameters of polygonometry class 4, 1 and 2 categories / P.A. Kareev // Bulletin of the SSGA. - 2002. - No. 7. P. 26 - 29.

4. Borodko, A.V. On the reconstruction of geodetic networks in the cities of the Moscow region / A.V. Borodko, G.N. Efimov // Geodesy and Cartography. - 2002. - No. 6. P. 26 - 29. 
Doi: https://doi.org/10.37547/tajet/Volume02Issue09-02

5. Rashidova D. I. Opportunity to use GIS technology of agriculture in Tashkent region. Theoretical \& Applied Science 85(05). 20-22 p. DOI: 10.15863/TAS.2020.05.85.5.

6. Frair, J. L., Fieberg, J., Hebblewhite, M., Cagnacci, F., DeCesare, N. J., \& Pedrotti, L. (2010). Resolving issues of imprecise and habitat-biased locations in ecological analyses using GPS telemetry data. Philosophical Transactions of the Royal Society B: Biological Sciences, 365(1550), 2187$2200 \mathrm{p}$. 